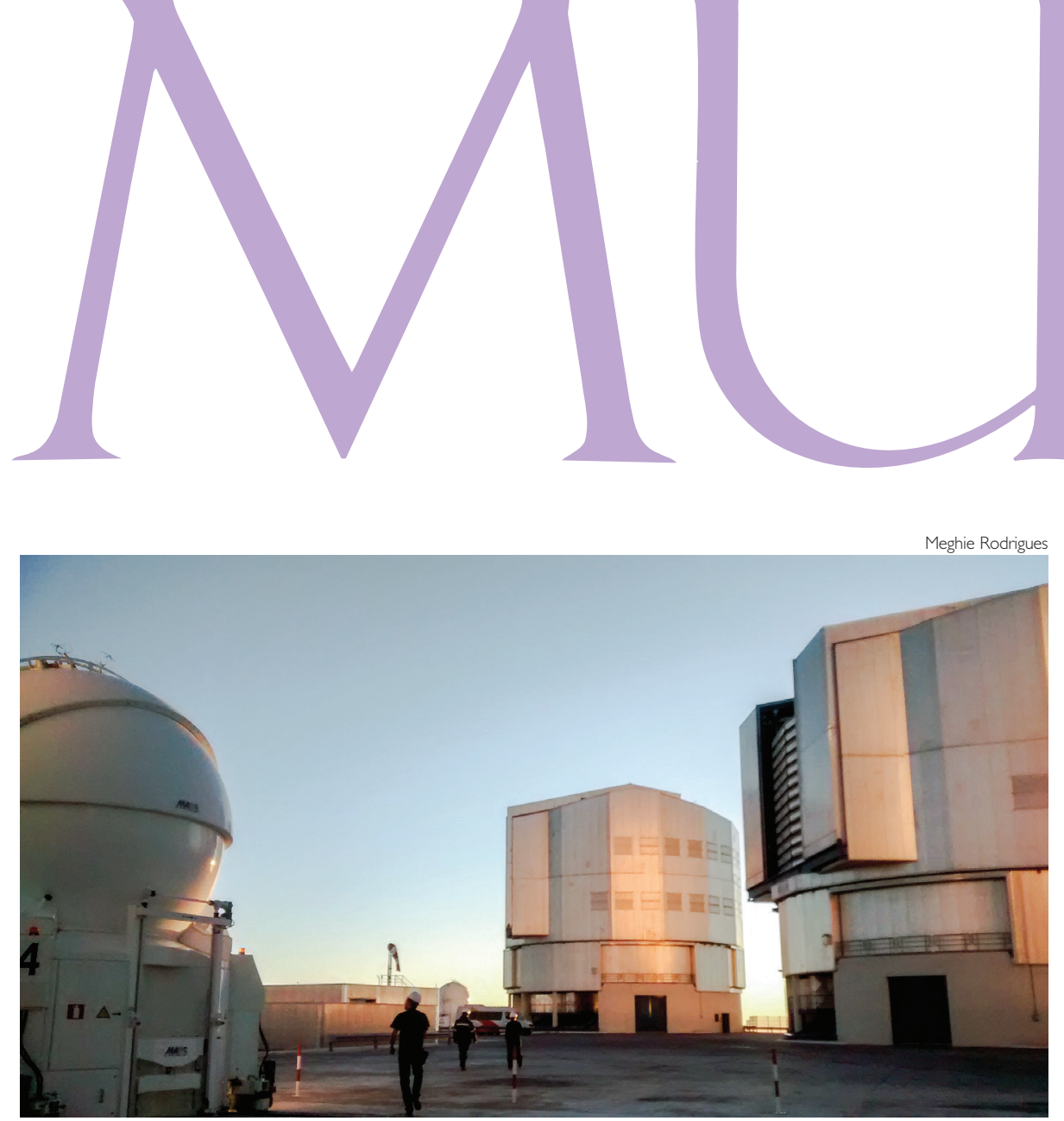

Fim de tarde na plataforma do VLT no Cerro Paranal, Chile

\title{
ASTRONOMIA
}

\section{Observatório Europeu do Sul aguarda definição do Brasil para completar megatelescópio}

Quando, em dezembro de 2010, o então ministro da Ciência, Tecnologia e Inovação (MCTI) Sérgio Rezende assinou o acordo de adesão que dava início ao processo de entrada do Brasil para o maior consórcio de pesquisa em astronomia da Europa, ninguém imaginava que, cinco anos depois, o fato ainda não estivesse concretizado. 0 que está em jogo, agora, não é se o Brasil entra ou não para o Observatório Europeu do Sul (ESO, na sigla em Inglês), mas sim quando. A adesão, que esteve em negociação por mais de quatro anos, foi aprovada no ano passado tanto pela Câmara quanto pelo Senado, e espera a publicação de um decreto presidencial para oficializar o país como o primeiro membro não-europeu a fazer parte do grupo.

Para além dos telescópios que já operam no deserto do Atacama, no norte do Chile, o próximo passo é a construção do European Extremely Large Telescope (E-ELT) no Cerro Armazones, a cerca de $1.200 \mathrm{~km}$ ao norte de Santiago. 0 objetivo é "que o telescópio veja sua primeira luz em 2024", conta Tim De Zeeuw, diretor-geral do ESO. O Brasil é, ele ressalta, peça-chave para que o projeto se concretize dentro do prazo e orçamento estipulados - ao custo de 1,2 bilhão de euros (R\$4,8 bilhões). Parte deste total, 270 milhões (quase $\mathrm{R} \$ 1,1$ bilhão), deverá ser pago pelo Brasil em parcelas, até 2021 , se o processo tiver a continuidade esperada. No fim de maio, os subcontratos de construção do domo e da estrutura principal do E-ELT foram assinados por empresas de países membros do ESO - o consórcio Ace, que consiste nas empresas Astaldi, Cimolai e Grupo EIE - no que foi o maior contrato para construção de um telescópio terrestre já assinado. o Brasil só poderia participar dessa concorrência para licitação quando for membro pleno do grupo - ou depois da chancela presidencial que oficializa a entrada do país no observatório e do pagamento da taxa de adesão de 130 milhões de euros e dos 140 milhões de euros em anuidades até 2021.

Mesmo sem sinal de pagamento, - Brasil já utiliza os telescópios do observatório desde 2010. O diretor do ESO diz que astrônomos brasileiros têm submetido propostas em um número menor do 

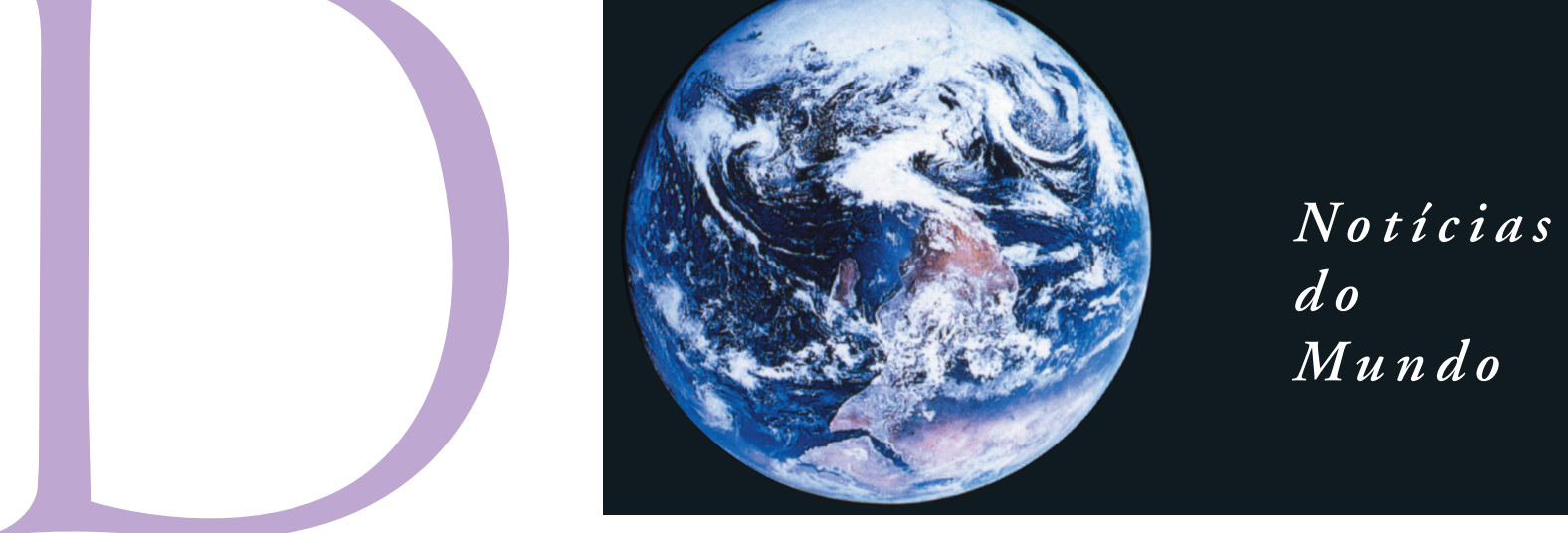

que poderiam, mas com a mesma taxa de sucesso que submissões de outros Estadosmembros. Como participante, o país teria "direito a todos os telescópios do ESO em operação e, tanto quanto pudermos, envolveremos instituições brasileiras em programas técnicos no desenvolvimento de instrumentação - o que já vem acontecendo em La Silla", ressalta ele.

De Zeeuw se refere a dois instrumentos atualmente sendo desenvolvidos em parceria com o Brasil: um deles é o pente de frequências laser, em processo na Universidade Federal do Rio Grande do Norte (UFRN), que aumenta a precisão de telescópios óticos e é usado na busca de planetas extra-solares. Será usado no telescópio de 3,6 metros em La Silla, no deserto chileno do Atacama. 0 outro é - Cassegrain U-band BrazilianESO Spectrograph (Cubes) que faz observações em ultravioleta e analisa a composição química de galáxias. Será usado no Very Large Telescope (VLT) no Cerro Paranal e está a cargo de pesquisadores do Instituto de Astronomia, Geofísica e Ciências Atmosféricas da Universidade de São Paulo (IAG-USP) em colaboração com o Laboratório
Nacional de Astrofísica (LNA), em Minas Gerais.

\section{PLANO DE CONTINGÊNCIA Dada a} incerteza sobre a entrada do Brasil na colaboração, o observatório dividiu o plano de execução do E-ELT em duas fases: uma primeira, em que será possível construir 90\% do telescópio mesmo sem a ajuda do país - e uma segunda, em que, com a adesão, o instrumento será finalizado. "Sem o Brasil, faremos 588 espelhos dos 698 totais para o E-ELT. Com o Brasil, seremos capazes de finalizar o projeto", diz Andreas Kaufer, diretor de operações do ESO em La Silla e Paranal.

A primeira fase de construção do telescópio teve início em meados do ano passado. Com uma área de três campos de futebol, o topo do Cerro Armazones já está nivelado e as estradas de acesso ao local também estão prontas. Agora, com a distribuição de licitações, a estrutura e o domo principal não devem demorar a sair. "Sem o Brasil, pode ser que o E-ELT não veja sua primeira luz em 2024, mas certamente a verá em 2026", assegura De Zeeuw. Com as negociações em curso com a Irlanda e Noruega o E-ELT ficará $90 \%$ pronto até 2024. 0 valor do pagamento anual que corresponderia a 2016, de acordo com Patrick Geeraert, diretor de administração do ESO, foi recalculado e reduzido em decorrência da situação econômica do país - se comparada à de 2010, ano em que o acordo de adesão foi assinado. 0 fato de a astronomia brasileira não estar no mesmo estágio de desenvolvimento da de outros Estados-membros do ESO também pesou nos descontos no valor da contribuição anual a ser paga. Geeraert diz que a contribuição anual depende da situação econômica dos paísesmembros nos três anos anteriores. Flutuações no PIB (Produto Interno Bruto) têm um grande peso no recálculo.

CONTROVÉRSIA A discussão sobre a entrada do Brasil no ESO começou em 2009 com a elaboração do Plano Nacional de Astronomia, lançado no ano seguinte pelo MCTI. De acordo com o presidente da Sociedade Astronômica Brasileira (SAB), Marcos Diaz, o tema teve ampla divulgação entre os astrônomos brasileiros, com a criação de grupos de discussão e de trabalho sobre o tema. A partir daí, "o recurso instrumental identificado como solução abrangente de médio e longo prazo foi a utilização dos telescópios do ESO", conta. 
